\title{
Review: nutritional and endocrine control of colostrogenesis in swine
}

\author{
H. Quesnel ${ }^{1 \dagger}$ and C. Farmer ${ }^{2}$ \\ ${ }^{1}$ PEGASE, INRA, Agrocampus Ouest, 35590 Saint-Gilles, France, ${ }^{2}$ Agriculture and Agri-Food Canada, Sherbrooke R \& D Centre, 2000 College St., Sherbrooke, QC, \\ Canada J1M OC8
}

(Received 9 July 2018; Accepted 30 November 2018)

\begin{abstract}
Colostrum plays an essential role in ensuring the survival, growth and health of piglets by providing energy, nutrients, immunoglobulins, growth factors and many other bioactive components and cells. Both colostrum yield and composition are highly variable among sows, yet mechanisms and factors that regulate colostrogenesis are not fully known. Unlike sow milk yield, sow colostrum yield is not highly determined by litter size and suckling intensity but is largely driven by sow-related factors. Colostrum synthesis is under hormonal control, with prolactin and progesterone concentrations prepartum having, respectively, positive and negative influences on colostrum yield. Less is known about the endocrine control of the end of colostrogenesis in swine, which is characterized by the closure of tight junctions in the mammary epithelium and the cessation of transfer of immunoglobulin $G(\mathrm{IgG})$ into lacteal secretions. Recent studies indicate that exogenous hormones may influence colostrogenesis. Inducing parturition by injecting prostaglandin F2 $\alpha$ on day 114 of gestation in combination with an oxytocin-like molecule reduced colostrum yield, and injection of prostaglandin F2 $\alpha$ alone either reduced colostrum yield or had no effect. Injecting a supraphysiological dose of oxytocin to sows in the early postpartum period delayed the tightening of mammary tight junctions, thereby prolonging the colostral phase and increasing concentrations of IGF-I and IgG and IgA in early milk. The development of strategies to improve colostrum composition in swine through maternal feeding has been largely explored but very few attempts were made to increase colostrum yield. This is most likely because of the difficulty in measuring colostrum yield in swine. The fatty acid content of colostrum greatly depends on the amount of lipids provided in the sow diet during late gestation, whereas the fatty acid profile is largely influenced by the type of lipid being fed to the pregnant sow. Moreover, various ingredients that presumably have immuno-modulating effects (such as fish oil, prebiotics and probiotics) increased concentrations of IgG, IgA and/or IgM in sow colostrum when they were provided during the last weeks of gestation. Finally, there is some evidence that sow nutrition during late gestation may influence colostrum yield but this clearly warrants more research. This review emphasizes that although progress has been made in understanding the control of colostrogenesis in swine, and that strategies exist to manipulate fat and immunoglobulin contents of colostrum, ways to increase colostrum yield are still lacking.
\end{abstract}

Keywords: colostrum, hormone, immunoglobulin, nutrition, sow

\section{Implications}

An early and high intake of colostrum is a major determinant of piglet survival in the first days after birth and is essential for ensuring the health and growth of piglets at least until weaning. However, both colostrum yield and composition are highly variable among sows. Better knowledge of endocrine and nutritional factors that participate in this variability is needed to define new strategies to manage reproductive sows to increase yield and quality of colostrum.

\footnotetext{
${ }^{\dagger}$ E-mail: helene.quesnel@inra.fr
}

\section{Introduction}

Colostrum intake is essential for piglet survival within the few days after birth and for piglet health and growth performance until weaning (Quesnel et al., 2012). Long-term effects were also reported, with colostrum intake being positively associated with piglet weight at weaning, at onset and end of the fattening period and being negatively correlated with piglet mortality during the nursery period (Declerck et al., 2016). Colostrum provides newborn piglets with the energy necessary for thermoregulation and body growth, with passive immunity needed for protection against pathogens, and with growth factors that stimulate growth and maturation of tissues and organs, especially the 
gastrointestinal tract (Quesnel et al., 2012). By transferring bioactive factors from the mother to the offspring, colostrum is crucial for the process of lactocrine signaling, which has an impact on the offspring much beyond the neonatal period. Bioactive components of colostrum include, for example, proteins, growth factors, peptides, oligosaccharides, fatty acid-derived molecules, steroids and microRNAs. The most striking example of a lactocrine-active factor is relaxin, which is a peptide hormone found in sow colostrum, that plays an important role in developmental programing of the female reproductive tract until puberty (Bartol et al., 2017).

In swine, colostrum can be defined as the first secretion of the mammary glands excreted for approximately $24 \mathrm{~h}$ after the onset of parturition. In both swine and ruminants, the major difference between colostrum and milk resides in the high concentrations of colostral immunoglobulins (Ig), specifically immunoglobulins $G(\lg G)$ in swine (and $\lg G 1$ in ruminants). Immunoglobulins $A$, although more abundant in colostrum than in milk, are not specific to colostrum and are therefore also present in milk throughout lactation. The composition of sow colostrum, especially in terms of $\mathrm{IgG}$ content, is highly variable among sows (Quesnel, 2011). Sow colostrum yield is estimated by summing the colostrum intakes of each piglet in the litter; it thus depends on the prediction model used to estimate individual colostrum intake. Based on Devillers' model (Devillers et al., 2004), colostrum yield averages $3.5 \mathrm{~kg}$ and ranges from $<1 \mathrm{~kg}$ to $>6.0 \mathrm{~kg}$ (Quesnel et al., 2012). Based on Theil's model (Theil et al., 2014a), it averages $6.0 \mathrm{~kg}$ with a range from 2.8 up to $8.5 \mathrm{~kg}$ (Vadmand et al., 2015). Nevertheless, regardless of the method used to estimate colostrum yield, it is greatly variable. The amount of colostrum needed by an average piglet (weighing $1.4 \mathrm{~kg}$ at birth) was estimated at $250 \mathrm{~g}$, or $180 \mathrm{~g} / \mathrm{kg}$ birth weight (calculated with Devillers' model; Quesnel et al., 2012). This amount would significantly reduce the risk of mortality, provide passive immunity and allow a slight weight gain. Based on this recommendation, Quesnel et al. (2012) estimated that at least one-third of sows do not produce enough colostrum to fulfill the needs of their litter.

The amount and composition of colostrum produced can be influenced by sow characteristics, such as endocrine status, nutritional status, immune status and level of stress, and by litter characteristics, especially vitality at birth. Environmental factors also could alter colostrum yield and composition through effects on the sows (e.g., heat stress is likely to reduce feed intake and cortisol concentration in sows). The complex interactions between these factors make it difficult to decipher their respective influence in the regulation of colostrogenesis. The present review will focus on the effects of sow endocrine status and nutrition because hormones play a major role in regulating colostrum synthesis, and nutrition could be a tool to manipulate colostrum yield and composition in herds.

\section{When does colostrogenesis take place?}

In the present review paper, colostrogenesis is defined as englobing both the synthesis of milk-specific constituents and the transfer of IgG into lacteal secretions. However, in order to efficiently investigate strategies to alter colostrogenesis in sows, it is imperative to know precisely when these two events occur. The synthesis of milk components takes place during late gestation, with the first lipid droplets being visible at 105 days of gestation (the gestational term of the sow is 115 days) (Kensinger et al., 1986) and the synthesis of lactose starting not before 3 to 4 days before parturition (Hartmann et al., 1984). The transfer of IgG from sow plasma to lacteal secretions slowly begins approximately 10 days before farrowing, increases 3 or 4 days before farrowing and is maximal on the day of farrowing (Huang et al., 1992). This suggests that colostrum synthesis, when defined by IgG transfer, is not entirely finished before parturition in sows. This is somewhat different from what occurs in dairy cows, with lgG1 transfer beginning several weeks before parturition, peaking a week prepartum and ceasing abruptly before calving (Barrington et al., 2001). Nevertheless, recent findings suggest that the transfer of $\operatorname{lgG}$ in dairy cows can persist at least until parturition (Gross et al., 2014).

During colostrogenesis, tight junctions between mammary epithelial cells (MECs) are 'leaky,' thereby allowing the paracellular transfer of constituents from maternal plasma to the alveolar compartment, notably of hormones, growth factors and Ig. The uptake of IgG by mammary glands in pigs could also be mediated by a Fc-specific receptor, the neonatal Fc receptor $(\mathrm{FcRn})$, as it is the case in ruminants (Barrington et al., 2001). Expression of the FcRn protein was demonstrated in porcine mammary tissue in the peripartum period, from 3 days before up to 1 day after parturition (Schnulle and Hurley, 2003; Palombo et al., 2018). However, the role of the FcRn in IgG transfer has not been demonstrated in swine. The uptake of $\lg \mathrm{A}$ in a polymeric form (plgA) could also be achieved via transcytosis mediated by the polymeric immunoglobulin receptor (plgR), whose transcript was shown in sow's mammary tissue (Schnulle and Hurley, personal communication). The relative importance of the passive $v$. the active transport of $\lg G$ and $\lg A$ transfer into sow colostrum is not known.

The composition of colostrum gradually changes between the onset of parturition (T0) and $24 \mathrm{~h}$ later (T24; Foisnet et al., 2010a). Lactose and fat contents increase while protein content decreases because of the drop in $\lg G$ and $\lg A$ concentrations (Theil et al., 2014b). In parallel, concentrations of $\mathrm{K}$ increase while $\mathrm{Na}$ concentrations decrease, as well as the $\mathrm{Na}: \mathrm{K}$ ratio (Quesnel, 2011). The decrease in the $\mathrm{Na}: \mathrm{K}$ ratio is indicative of the development of tight junctions between cells in the mammary epithelium. Concentrations of IgG in colostrum at T24 are positively correlated with the $\mathrm{Na}: \mathrm{K}$ ratio in colostrum at $\mathrm{T} 24$, whereas the drop in $\mathrm{IgG}$ concentrations in colostrum between T0 and T24 is negatively correlated to that same variable (Quesnel, 2011). These relations are consistent with the fact that the cessation of $\mathrm{lgG}$ 
transfer into lacteal secretions and the closure of tight junctions are part of the process, marking the end of colostrogenesis and the initiation of lactation.

\section{Sow v. piglets, who drives?}

In swine, it is well known that milk production is stimulated by the action of suckling from piglets, and thus depends on litter size and weight of piglets. Moreover, the estimation of colostrum yield actually corresponds to the consumption of colostrum by the litter. Therefore, it has long been argued that colostrum yield mainly depends on litter characteristics. However, there is now a large body of evidence that even though colostrum yield may be influenced by the global vitality of the litter at birth, it also largely depends on the capacity of the sow to produce colostrum (Farmer and Quesnel, 2009).

\section{Endocrine control of colostrogenesis}

\section{Role of endogenous hormones}

In swine, the prepartum peak of prolactin is essential for colostrogenesis (Farmer et al., 1998) and is brought about by the drop in progesterone concentrations (Taverne et al., 1982). In primiparous sows, delays in the decrease in progesterone and in the increase in prolactin relative to the onset of parturition were greatly associated with a reduced yield of colostrum (Foisnet et al., 2010a). Furthermore, the relative concentrations of prolactin and progesterone during the prepartum period were recently shown to influence colostrum yield. Primiparous sows that had lower progesterone concentrations associated with a tendency for greater prolactin concentrations (high prolactin to progesterone ratio) during the 2 days before and the day of parturition produced more colostrum $(+0.6 \mathrm{~kg})$ than sows that had a low prolactin to progesterone ratio (Loisel et al., 2015). There were no concomitant changes in the concentrations of macronutrients in colostrum, indicating an absence of dilution effect. The greater colostrum concentrations of progesterone at the onset of parturition were also negatively related with colostrum yield in sows from parities one to eight, with sows having concentrations of progesterone $>4.5 \mathrm{ng} / \mathrm{ml}$ producing $1.6 \mathrm{~kg}$ less colostrum than those having progesterone concentrations of $<4.5 \mathrm{ng} / \mathrm{ml}$ (Hasan et al., 2018). It is however important to mention that even though lower peripartum concentrations of prolactin are observed in primiparous than in multiparous sows (Quesnel et al., 2013), this does not necessarily translate into a lower production of colostrum. Indeed, significant discrepancies exist between studies on the effect of sow parity on colostrum yield (Table 1). Greater colostrum yield was reported in young sows compared with older sows (Decaluwé et al., 2013; Quesnel, unpublished data), while Devillers et al. (2007) reported that sows of parities two and three tended to produce more colostrum than primiparous and older sows. Finally, Boonraungrod et al. (2018) recently reported that multiparous sows produced more colostrum than primiparous sows.

Besides progesterone and prolactin, other hormones also undergo drastic changes peripartum. Among them, estrogens and glucocorticoids whose concentrations increase during the week and the day before parturition, respectively (Foisnet et al., 2010a), are considered to be involved in the regulation of lactogenesis in rodents and ruminants. To the best of our knowledge, however, a role for estrogens and glucocorticoids in the control of colostrogenesis has not yet been described in swine. Oxytocin, which is essential for fetus expulsion, peaks during parturition. The peak of oxytocin may be too late to participate in the regulation of colostrum nutrient synthesis. However, its amplitude and duration may influence the transfer of IgG into lacteal secretions by delaying the closure of tight junctions between mammary epithelial cells.

Finally, a link between colostrum yield and farrowing kinetics was reported in primiparous sows (Quesnel, 2011). The rhythm of piglet births during the onset of parturition was lower in sows with a low colostrum production $(<3 \mathrm{~kg})$ than in sows with a medium $(3-4 \mathrm{~kg})$ or high $(>4 \mathrm{~kg})$ production. It can be suggested that abnormalities in the endocrine status of sows in late pregnancy may affect the processes of both parturition and colostrogenesis, and these two processes being partly regulated by common hormones, such as progesterone and maybe estrogens and glucocorticoids.

Colostrum yield was shown to be positively correlated with plasma concentrations of IGF-I in prepartal sows (Foisnet et al., 2010a). Accordingly, it was suggested that the $20 \%$ increase in colostrum yield observed when sows were fed a fermented potato protein product for 7 days before expected farrowing could be due to greater IGF-I concentrations in sow plasma (Wavreille et al., 2010). It can be hypothesized that IGF-I could stimulate lactogenesis because it can act as a mitogenic factor or an anabolic hormone that favors nutrient uptake by MEC, or both. However, these observations are insufficient to conclude for a stimulatory effect of IGF-I on colostrum production.

Table 1 Colostrum yield according to sow parity

\begin{tabular}{|c|c|c|}
\hline $\begin{array}{l}\text { Colostrum yield }(\mathrm{kg}) \text { according to sow } \\
\text { parity }\end{array}$ & $n^{1}$ & Reference \\
\hline $\begin{array}{l}\text { Parity } 1(3.4 \mathrm{~kg})^{a}<\text { Parities } 2 \text { to } 3 \\
\quad(4.3 \mathrm{~kg})^{\mathrm{b}}\end{array}$ & 40 & Devillers et al., 2007 \\
\hline $\begin{array}{l}\text { Parities } 1 \text { to } 3(3.7 \mathrm{~kg})^{\mathrm{a}}>\text { Parities } 4 \text { to } 7 \\
(2.8 \mathrm{~kg})^{\mathrm{b}}\end{array}$ & 37 & Decaluwé et al., 2013 \\
\hline $\begin{array}{l}\text { Parities } 1 \text { to } 2(3.7 \mathrm{~kg})^{\mathrm{a}}>\text { Parities } 3 \text { to } 8 \\
(3.2 \mathrm{~kg})^{\mathrm{b}}\end{array}$ & 121 & Quesnel, unpublished \\
\hline $\begin{array}{l}\text { Parity } 1(4.8 \mathrm{~kg})^{\mathrm{a}}<\text { Parities } 2 \text { to } 5 \\
(5.0 \mathrm{~kg})^{\mathrm{b}}\end{array}$ & 183 & $\begin{array}{l}\text { Boonraungrod et al., } \\
2018\end{array}$ \\
\hline
\end{tabular}

${ }^{1}$ Number of sows.

${ }^{\mathrm{ab}}$ Average colostrum yield with different letters differed $(P<0.05)$. 
Effects of exogenous hormones

Inducing parturition. A key factor for successful intensive farrowing management is farrowing supervision, hence natural and synthetic prostaglandin F2 $\alpha$ (PGF $2 \alpha$ ) are commonly used in pig farms to induce parturition. Although one study reported that inducing parturition on day 114 of gestation (i.e., one day before the average term) decreased colostrum yield, other studies showed no significant effect (Table 2). Nevertheless, farrowing induction on day 113 of gestation induced transient alterations in plasma hormonal concentrations and colostrum composition (Foisnet et al., 2011). Increases in prolactin and cortisol concentrations were observed $1 \mathrm{~h}$ after the injection of PGF2 $\alpha$. Colostrum collected at the onset of parturition (T0) contained more lactose and less IgA when parturition was induced, whereas colostrum composition at T24 did not differ between sows with natural or induced farrowing (Foisnet et al., 2011). Farrowing induction had no effect on colostral concentrations of IgG (Foisnet et al., 2011; Otto et al., 2017). It is apparent that if farrowing induction is performed not earlier than one day before the expected farrowing date (based on individual monitoring or on the average farrowing date in the herd), no negative impact on colostrum yield is expected. However, the effect of farrowing induction on IgA concentrations and on the subsequent occurrence of neonatal diarrhea warrants further investigation.

Preventing premature parturition. In a retrospective study, based on 61000 farrowing records, a 10\% occurrence of early parturition ( $<114$ days) was observed (Vanderhaeghe et al., 2011). Premature parturition may affect the birth weight, survival and growth of piglets and it interferes with the management procedures on the farm. It is thus important to prevent premature parturition in herds where its incidence is high. This can be achieved by administering an analog of progesterone (altrenogest) to maintain plasma concentrations of progesterone during the last few days of pregnancy. Administration of altrenogest from days 109 to 112 or 113 of gestation did not affect colostrum yield, likely because the treatment delayed farrowing and main hormonal changes without affecting the relative chronology of these changes (Foisnet et al., 2010b). Such a treatment was tested on a large scale in commercial herds, with no report of negative impact on piglet survival until weaning (Vanderhaeghe et al., 2011), which is consistent with the lack of negative effect on colostrum yield.

Injecting oxytocin. As mentioned earlier, the composition of colostrum is affected by the status of tight junctions between mammary epithelial cells. Therefore, the ability to manipulate mammary tight junctions in the late colostral phase could allow Ig concentrations to be maintained at higher levels for a longer period of time, thereby increasing the quality of early milk. Injecting a supraphysiological dose of oxytocin to sows on day 2 of lactation (i.e., between 12 and $20 \mathrm{~h}$ after birth of the last piglet) increased the $\mathrm{Na}: \mathrm{K}$ ratio $(0.48 \mathrm{v} .0 .28)$ and concentrations of IGF-I $(78.1$ v. $37.2 \mathrm{ng} / \mathrm{ml}), \operatorname{lgG}(18.8 \mathrm{v} .6 .6 \mathrm{mg} / \mathrm{ml})$ and $\mathrm{lgA}(4.1 \mathrm{v}$. $2.7 \mathrm{mg} / \mathrm{ml}$ ) in milk collected $8 \mathrm{~h}$ after the injection (Farmer et al., 2017). The injection of oxytocin in the early postpartum period therefore delayed the occurrence of tightening of mammary tight junctions and prolonged the colostral phase, thereby having beneficial effects on the composition of early milk.

\section{Effects of nutrition on colostrogenesis}

The development of strategies to improve colostrum composition through maternal feeding has been largely explored, with a special focus on colostral fat and Ig because both are sensitive to nutritional changes. In contrast, very few attempts were made to increase colostrum yield, which is most likely due to the difficulty in measuring the amount of colostrum produced. Most recent attempts focused on maternal feeding during late gestation, when milk-specific constituents are synthetized. Alternatively, long-term strategies might aim at increasing mammary gland development. Although it is well known that milk yield depends on the number of mammary epithelial cells present at the onset of lactation (Head and Williams, 1991), it is not known whether this is also the case for colostrum production. Nutritional strategies to improve colostrum synthesis might also aim at managing sow body reserves and metabolic status during late pregnancy and this is covered in more

Table 2 Colostrum yield and gestation length in sows with farrowings induced on day 113 or 114 of gestation

\begin{tabular}{|c|c|c|c|c|c|c|}
\hline \multirow[b]{2}{*}{ Treatment } & \multicolumn{2}{|c|}{ Colostrum yield, $\mathrm{kg}$} & \multicolumn{2}{|c|}{ Gestation length, days } & \multirow[b]{2}{*}{$n^{1}$} & \multirow[b]{2}{*}{ Reference } \\
\hline & Control & Induced $^{2}$ & Control & Induced $^{2}$ & & \\
\hline PGF2 $\alpha^{3}$ analog on day 114 & 4.16 & $3.37^{* *}$ & 113.3 & $114.6^{*}$ & $40 \mathrm{P} 1$ to $\mathrm{P} 6$ & Devillers et al., 2007 \\
\hline PGF2 $\alpha^{3}$ analog on day 113 & 4.47 & $3.95^{\dagger}$ & 113.7 & 114.0 & $47 \mathrm{P} 1$ & Foisnet et al., 2011 \\
\hline PGF2 $\alpha^{3}$ analog on day 114 & 4.81 & 4.66 & - & - & $96 \mathrm{P} 3$ to $\mathrm{P7}$ & Otto et al., 2017 \\
\hline PGF2 $\alpha^{3}$ analog on day 114 & 4.84 & 4.90 & 114.8 & 114.7 & $130 \mathrm{P} 1$ to $\mathrm{P} 5$ & Boonraungrod et al., 2018 \\
\hline PGF2 $\alpha^{3}$ analog on day $114+$ carbetocin $^{4}$ & 4.84 & $4.05^{*}$ & 114.8 & 115.1 & $133 \mathrm{P} 1$ to $\mathrm{P} 5$ & Boonraungrod et al., 2018 \\
\hline
\end{tabular}

${ }^{1}$ Total number of sows and parity (P).

${ }^{2}$ Treatment effect: ${ }^{* *} P<0.01,{ }^{*} P<0.05,{ }^{\dagger} P<0.10$.

${ }^{3}$ Prostaglandin $\mathrm{F} 2 \alpha$.

${ }^{4}$ Carbetocin is an oxytocin-like molecule with long-acting properties; it was injected $24 \mathrm{~h}$ after the PGF2 $\alpha$ analog 
Quesnel and Farmer

Table 3 Nutritional manipulation of colostrum yield and effects on macrochemical composition of colostrum in sows

\begin{tabular}{|c|c|c|c|c|c|}
\hline \multirow[b]{2}{*}{ Treatment $^{1}$} & \multirow[b]{2}{*}{ Duration } & \multicolumn{2}{|c|}{ Effects on colostrum ${ }^{2}$} & \multirow[b]{2}{*}{$n^{3}$} & \multirow[b]{2}{*}{ Reference } \\
\hline & & Yield & Composition & & \\
\hline \multicolumn{6}{|l|}{ Level of feeding } \\
\hline 4.5 v. $1.5 \mathrm{~kg} / \mathrm{d}$ & Day 108 to term & $\pi^{\dagger}$ & $\begin{array}{l}\text { त lactose* } \\
\text { y protein* }\end{array}$ & $50 \mathrm{P} 2$ to $\mathrm{P} 7$ & Decaluwé et al., 2014 \\
\hline \multicolumn{6}{|c|}{ Source or level of fat or dietary fiber } \\
\hline Pectin residue $^{4}$ & Mating to day 107 & $\pi^{*}$ & $\begin{array}{l}\boldsymbol{\lambda} \text { lactose* } \\
\text { y protein* } \\
\text { y energy* }\end{array}$ & 20 & Theil et al., 2014a \\
\hline Various sources of fat ${ }^{5}$ & Day 108 to term & NS & $\begin{array}{l}\text { y lactose } \\
\text { y } \mathrm{DM}^{+6}\end{array}$ & 40 & Theil et al., 2014a \\
\hline $\begin{array}{l}\text { High dietary fiber }{ }^{7} \\
\text { Various ingredients }\end{array}$ & Day 106 to term & NS & $\pi \mathrm{fat}^{*}$ & $29 \mathrm{P} 1$ & Loisel et al., 2013 \\
\hline $\mathrm{CLA}^{1}, 1.3 \%$ & Day 108 to term & $y^{\dagger}$ & $\geqslant \mathrm{fat}^{\dagger}$ & 23 P1-P3 & Krogh et al., 2012 \\
\hline $\mathrm{CLA}^{1}, 0.75,1.5$ or $2.25 \%$ & Day 85 to term & NS & $y$ fat & $48 \mathrm{MP}$ & Wu et al., 2015 \\
\hline $\mathrm{HMB}^{1}, 2.0 \mathrm{~g} / \mathrm{d}$ & Day 111 to term & - & $\boldsymbol{\gamma}$ fat ${ }^{* *}$ & $68 \mathrm{MP}$ & Nissen et al., 1994 \\
\hline $\mathrm{HMB}^{1}, 2.5 \mathrm{~g} / \mathrm{d}$ & Day 108 to term & $N S^{8}$ & No effect & $16 P 2$ & Flummer and Theil, 2012 \\
\hline Arginine, $25 \mathrm{~g} / \mathrm{d}$ & Day 30 to weaning & NS & $\begin{array}{l}\text { y } \text { lactose }^{*} \\
\boldsymbol{\lambda} \text { protein }^{\dagger} \\
\boldsymbol{\lambda} \text { IGF-I }^{\dagger}\end{array}$ & $21 \mathrm{MP}$ & Krogh et al., 2016 \\
\hline Yeast derivates, $2 \mathrm{~g} / \mathrm{kg}$ diet & Gestation + lactation & $\pi^{*}$ & $7 \mathrm{fat}^{*}$ & 37 P1-P8 & Hasan et al., 2018 \\
\hline \multicolumn{6}{|c|}{$\begin{array}{l}{ }^{1} \text { CLA: Conjugated linoleic acid; HMB: B-hydroxy B-methyl butyrate. } \\
{ }^{2} \text { Treatment effect: }{ }^{* \star} P<0.01,{ }^{*} P<0.05,{ }^{\dagger} P<0.10, \text { NS: not significant. } \\
\text { 3Total number of sows and parity (P, when known). MP: multiparous sows. } \\
{ }^{4} \mathrm{~A} \text { high-fiber diet formulated with pectin residue (32\% DM, insoluble dietary fiber) was compared with a high-fiber diet rich in potato pulp (40\% DM, soluble dietary } \\
\text { fiber). }\end{array}$} \\
\hline
\end{tabular}

detail by Quesnel et al. (2015). However, the fact remains that the relation between sow metabolic state during gestation and colostrum yield is not clear, with discrepancies between findings.

\section{Sow nutrition and colostrum yield}

Manipulating circulating concentrations of prolactin. Given the effects of prepartum prolactin concentrations on colostrum yield, the development of strategies to influence prolactin concentrations through nutritional approaches is warranted. Silymarin, an extract from the milk thistle plant (Silybum marianum), is known for its hyperprolactinemic properties. Yet an attempt to induce hyperprolactinemia in sows before parturition by providing silymarin was not successful (Loisel et al., 2014). To the best of our knowledge, there are no other known nutritional means to increase prolactin concentrations in swine.

Manipulating circulating concentrations of progesterone. Circulating concentrations of progesterone can be influenced by the level of feeding. Indeed, in gilts and ewes, progesterone concentrations were reduced with a high feeding level, likely because of an increase in metabolic clearance rate (Banchero et al., 2015). Supplementing ewes with energy during the last week of pregnancy accelerates the decline in circulating progesterone that, in turns, increases colostrum yield (Banchero et al., 2015). However, increasing sow feed intake for the last 2 weeks of pregnancy did not affect circulating concentrations of progesterone and piglet weight gain during the first 2 days postpartum, indicating that colostrum yield was unaltered (Miller et al., 2004). Authors suggested that this absence of effect could be tied to the stimulatory effect of increased feeding level (via greater insulin and IGF-I concentrations) on the production of progesterone by corpora lutea, occurring concurrently with the increased clearance rate of progesterone. This problem may be overcome by imposing a high level of feeding for a shorter period of time at the beginning of luteolysis (i.e., 2 days before parturition) in order to accelerate the decrease in progesterone without stimulating its synthesis.

Manipulating colostrum yield. The few published experiments where nutritional attempts were made to stimulate colostrum yield used various strategies based on feeding level, source or level of fat and dietary fiber, and feeding specific nutrients (Table 3). A high feeding level (three times $1.5 \mathrm{~kg}$ daily compared with $1.5 \mathrm{~kg} /$ day) during the last week of gestation tended to increase colostrum yield from 3.5 to $4.0 \mathrm{~kg}$ (Decaluwé et al., 2014). This effect may be related to the greater lactose content of colostrum from overfed sows, 
lactose being the major osmotic factor that favors water transfer into lacteal secretions. Interestingly, Decaluwé et al. (2014) also showed that sow body condition had more impact on colostrum yield than feeding level. The highest colostrum yield was achieved when sows entered the farrowing unit with a moderate body condition (i.e., with a backfat thickness between 17 and $23 \mathrm{~mm}$ ) and were fed the high plane of nutrition for a week before farrowing.

Theil et al. (2014a) combined two feeding strategies by providing various levels and sources of dietary fiber during most of gestation (from mating to day 107) and then various levels and sources of fat during the last week of gestation (Table 3). The gestation diet, but not the prefarrowing diet, influenced colostrum yield, with sows fed pectin residue (rich in insoluble fiber) producing more colostrum than sows fed potato pulp (rich in soluble fiber; 6.2 v. $4.6 \mathrm{~kg}$ ). It is not clear why sows fed pectin residue produced more colostrum but this was consistent with a greater lactose content in colostrum. However, when sows were fed sugar beet pulp (rich in soluble dietary fiber), their colostrum yield was intermediate compared with that of sows fed pectin residue or potato pulp, despite their higher lactose content in colostrum. Loisel et al. (2013) found no effect of high dietary fiber providing both soluble and insoluble fibers $(23 \%$ of dietary fiber originating from a mixture of soybean hulls, wheat bran, undecorticated sunflower meal and sugar beet pulp) on colostrum yield when compared with a low fiber diet (13\% of dietary fiber). Nevertheless, this high-fiber diet increased by nearly $60 \%$ the colostrum intake of low birth weight-piglets $(<900 \mathrm{~g})$ and was associated with lower piglet mortality until weaning. Clearly the effects of dietary fiber source on colostrum yield or composition and their underlying mechanisms need further attention.

The potential effects of various specific ingredients, namely conjugated linoleic acid (CLA), the leucine metabolite B-hydroxy B-methyl butyrate (HMB) and arginine, on colostrum yield were also investigated, with no significant effects being reported (Table 3 ). A trend for lower colostrum yield was reported in response to CLA supplementation during the last week of gestation (Krogh et al., 2012).

Collectively, these data indicate that nutrition in late pregnancy is important for colostrum yield of sows, but that more investigations are needed to determine which nutrients or feeding strategies are most effective and which part of gestation (last week, last three weeks or last third) is most critical for colostrum production.

\section{Sow nutrition and colostral fat content}

The effects of sow nutrition, encompassing feed intake, energy intake and source, and protein intake, on macrochemical composition of colostrum, have been extensively reviewed, as well as the effects of vitamins and minerals on microchemical composition (Farmer and Quesnel, 2009). The present review therefore only covers most recent findings, with a special focus on fat because it is by far the most labile macronutrient of colostrum. The fatty acid content of colostrum greatly depends on the amount of lipids provided in the sow diet during late gestation, whereas the fatty acid profile is largely influenced by the type of lipid being fed to the pregnant sow (Farmer and Quesnel, 2009). Additional colostral fat may be used, to a certain extent, as supplementary energy by the piglet and it may also increase lipid accretion, thereby enabling piglets to maintain a constant body temperature. Moreover, specific fatty acids are important for piglet maturation, such as polyunsaturated fatty acids (PUFA) which are known to play a role in brain development and function. Various studies were therefore carried out with the goal of increasing the amount of polyunsaturated fats in sow colostrum. This was successfully achieved via the inclusion of various fish oils or linseed oil in the diet of pregnant sows (Rooke et al., 1998; 2001). Supplementation of soybean oil in the diet of sows during the last week of pregnancy also increased the fat content and the concentrations of polyunsaturated fatty acids in colostrum (Bai et al., 2017). Dietary CLA also affects the fatty acid composition of colostral fat in sows, increasing saturated fatty acids and decreasing monounsaturated fatty acids (Bee, 2000).

Besides the addition of fat to the maternal diet, providing additional dietary fiber in late gestation may be another way of increasing the fat content of colostrum. Loisel et al. (2013) demonstrated that feeding $23.4 \%$ compared with $13.3 \%$ dietary fiber to sows from day 106 of gestation until parturition increased colostral fat from $8.3 \%$ in control sows to $10.7 \%$ in treated sows. Such an effect could not be attributed to dietary lipid intake or mobilization of body lipids since they did not differ significantly between sows fed the low and the high level of dietary fiber. This effect may be due to the fact that dietary fiber increases plasma concentrations of short chain fatty acids, including acetate which can be used by the mammary gland as precursors for de novo synthesis of lipids (Linzell et al., 1969).

Colostral fat content was also increased by supplementing the sow diet with the leucine metabolite HMB $(2.0 \mathrm{~g} /$ day of $\left.\mathrm{Ca}(\mathrm{HMB})_{2}\right)$ in the last 3 to 4 days before parturition $(6.9 \mathrm{v}$. 4.9\%; Nissen et al., 1994). The mechanism of action of HMB is likely to be linked to its lipolytic effect, causing fat mobilization and elevated plasma concentrations of non-esterified fatty acids that can be used for de novo fat synthesis (Theil et al., 2014b). However, Flummer and Theil (2012) could not reproduce this effect of HMB supplementation on colostrum composition (Table 3). Lastly, supplementing the sow diet with glutamine and glutamate can also affect colostral fat concentration. Providing the two amino acids as Aminogut $(1.5 \% \mathrm{w} / \mathrm{w})$ during the last week of gestation increased colostral fat by $60 \%$ (7.4 v.4.6\%, Santos de Aquinos et al., 2014). However, it is not known if glutamine or glutamate stimulate lipid synthesis or act as substrates for de novo lipogenesis.

\section{Sow nutrition and immunoglobulin contents of colostrum} Numerous ingredients that presumably have immunomodulating effects were tested for their potential beneficial effects on the Ig concentrations of swine colostrum. These 
Quesnel and Farmer

Table 4 Nutritional manipulation of immunoglobulin concentrations in colostrum in sows, presumably through immunomodulating effects of active components ${ }^{1}$

\begin{tabular}{|c|c|c|c|}
\hline Treatment & Duration $^{2}$ & Effect $^{3}$ & References $^{4}$ \\
\hline Conjugated linoleic acid, $0.5 \%$ & 8 days & $\boldsymbol{\gamma} \lg G$ & Bontempo et al., 2004 \\
\hline Conjugated linoleic acid, $0.75,1.5$ or $2.25 \%$ & 7 days & $\pi \lg G, \lg A, \lg M$ & Corino et al., 2009 \\
\hline Conjugated linoleic acid, $0.5 \%$ & 4 weeks & $\pi \lg G, \lg A, \lg M$ & Wu et al., 2015 \\
\hline Shark liver oil & 35 days & $\pi \lg G_{1}=\lg A$ & Mitre et al., 2005 \\
\hline Phytogenic feed additive (source of essential oils) & 1 week & $\pi \lg G, \lg A$ & Wang et al., 2008 \\
\hline Plant extract & 1 week & $y \lg G, \lg A$ & Ilsley et al., 2003 \\
\hline Saponins (plant extract) & 3 weeks $^{5}$ & $=\lg G, \lg A$ & Ilsley and Miller, 2005 \\
\hline Oregano essential oil & Whole gestation & $=\lg G, \lg A$ & Ariza-Nieto et al., 2011 \\
\hline Non-specific immunostimulants ${ }^{6}$ & 4 to 6 weeks & $\geqslant \lg G$ & Krakowski et al., 2002 \\
\hline Mannan oligosaccharides & 2 weeks & $\begin{array}{l}\boldsymbol{\lambda} \lg \mathrm{M}_{\mathbf{1}} \\
\quad=\lg \mathrm{G}, \lg \mathrm{A}\end{array}$ & Newman and Newman, 2001 \\
\hline Mannan oligosaccharides & 3 weeks & $\pi \lg G, \lg A, \lg M$ & O'Quinn et al., 2001 \\
\hline Fructo oligosaccharides & 28 days & $=\lg G, \geqslant \lg A$ & Le Bourgot et al., 2014 \\
\hline Astragalus polysaccharides & 1 week & $\approx \lg , \lg M$ & Tan et al., 2017 \\
\hline Yeast derivates ${ }^{7}$ & Gestation & $=\lg G, \lg A, \lg M$ & Bass et al., 2012 \\
\hline Yeast derivates $^{8}$ & Gestation & $=\lg G, \lg A, \lg M$ & Hasan et al., 2018 \\
\hline Fermented liquid feed & 2 weeks & $\begin{array}{l}\pi \lg G, \lg A \\
=\lg M\end{array}$ & Demečková et al., 2003 \\
\hline Saccharomyces cerevisiae boulardii & 21 days & $\approx \lg G, \lg A$ & Guillou et al., 2012 \\
\hline Saccharomyces cerevisiae ${ }^{9}$ & Gestation & $\pi \lg G,=\lg A$ & Zanello et al., 2013 \\
\hline
\end{tabular}

${ }^{1}$ Published in part by Farmer and Quesnel (2009).

${ }^{2}$ Duration of treatment before parturition.

${ }^{3} \boldsymbol{7}$ increased immunoglobulin (Ig) concentrations; = no significant effect on Ig concentrations; $\boldsymbol{y}$ reduced $\lg$ concentrations.

${ }^{4}$ The list of references is given in Supplementary material $\mathrm{S1}$.

${ }^{5}$ From days 72 to 93 of pregnancy.

${ }^{6}$ Factors that induce non-specific defense mechanisms of the organism toward the viral and bacterial pathogens.

${ }^{7}$ Whole extract derived from $P$. guilliermondii.

${ }^{8}$ Whole extract derived from S. cerevisiae.

${ }^{9}$ Two strains were tested: S. cerevisiae strain CNCM I-4407 and S. cerevisiae var. boulardii strain CNCM I-3799. A third strain (S. cerevisiae strain LC 10-05) had no effect on colostral lgG and $\lg A$.

ingredients belong to various families of components: specific fatty acids (such as CLA and fish oils), plant extracts (as essential oils), prebiotics (mannan oligosaccharides (MOS) or fructo oligosaccharides (FOS)) and probiotics (mainly Saccharomyces cerevisiae boulardii), or ingredients containing pre- or probiotics (fermented liquid feed). When fed to late pregnant sows, many of these ingredients increased $\lg G$, $\lg A$ and (or) IgM concentrations in colostrum (Table 4).

As mentioned earlier, long-chain PUFA of the $n-6$ and $n-3$ series have received a lot of attention in sow nutrition because of their role in brain development. They may also have health-promoting properties through impacts on inflammatory and immune status. Conjugated linoleic acid which is the collective name for isomers of linoleic acid (an n-6 PUFA) was efficient in increasing Ig contents of colostrum, at various doses (Table 4). This effect was likely due to the increase in Ig concentrations in sow serum, itself potentially mediated through an increase in interleukin-2 synthesis in response to CLA supplementation (Wu et al., 2015). The increase in colostral $\lg$ observed when the sow diet was supplemented with shark-liver oil was also associated with greater lg concentrations in sow plasma. Shark-liver oil is a source of two bioactive lipids, the alkylglycerols and $\mathrm{n}-3$ PUFA, and the increased plasmatic Ig production by sows was mainly attributed to alkylglycerols. These supplementations improved the maternal transfer of passive immunity to the piglets, as indicated by greater IgG concentrations in piglet blood. Interestingly also, there are recent indications that feeding fish oil during the last month of gestation can affect the antioxidant capacity of sow colostrum (Shen et al., 2015), yet much remains to be learned on this topic.

A wide range of beneficial properties are also attributed to plant-derived compounds, among them antimicrobial activity, antioxidant property and effects on the immune system. However, both positive and negative effects on colostrum Ig content were reported (Table 4).

Finally, probiotics and prebiotics receive considerable attention currently because of many potential beneficial effects on health. In short, probiotics are living organisms which colonize the gastrointestinal tract while prebiotics are fermented compounds that induce changes in gut microbiota. Effects on gut microbiota may be accompanied by beneficial effects on the gut immune system with consequences on the whole organism. Providing living bacteria (Lactobacillus strains in fermented liquid feed) or living cells (as Saccharomyces cerevisiae) or prebiotics MOS or FOS was shown to increase $\lg G$ or $\lg A$ concentrations in colostrum 
(Table 4). In contrast, yeast extract provided throughout gestation had no effect on colostral Igs. Interestingly, however, a recent study reported no effects of prebiotics supplementation on $\lg G, \lg A$ or $\lg M$ content in sow colostrum but positive effects on both fat content and colostrum yield were observed (Hasan et al., 2018). Multiparous sows were fed a control diet or a control diet supplemented with $2 \mathrm{~g}$ of yeast derivatives throughout pregnancy. This extract contained a mix of mannan oligosaccharides and polysaccharides, glucomannoproteins and betaglucans. Protein and lactose contents of colostrum were not affected, whereas fat content was increased by $21 \%$ and colostrum yield by $24 \%$.

In conclusion, the most promising results on colostrum Ig content were obtained with CLA, prebiotics in the form of MOS and FOS, and living yeast cells, while the effects of plant extracts and yeast extracts are far less convincing.

\section{Conclusions}

Colostrum is crucial for the survival, development and health of piglets so that knowledge about mechanisms that regulate or influence colostrogenesis is essential. Although progress has been made in understanding the factors that regulate colostrum yield and composition, including the endocrine regulation and the impact of sow nutrition, several essential questions remain unanswered. Namely, when is colostrum synthetized precisely? What are the impacts of sow nutrition and metabolic status during late gestation? Does mammary development affect colostrum yield? Promising results on colostrum yield or quality were obtained by manipulating levels and sources of dietary fat and fiber during late gestation, or by supplementing sow diets with pre- and probiotics. In the future, nutritional strategies should be tested in commercial farms, using large numbers of animals, in order to investigate whether, beyond their effects on colostrum yield or composition, they affect piglet performance in terms of survival, growth, health and robustness at weaning.

\section{Acknowledgement}

None.

\section{Declaration of interest}

The authors declare that they have no competing interests.

\section{Ethics statement \\ Not applicable.}

\section{Software and data repository resources}

No data were deposited in an official repository.

\section{Supplementary material}

To view supplementary material for this article, please visit https://doi.org/10.1017/S1751731118003555

\section{References}

Bai YS, Wang CQ, Zhao X, Shi BM and Shan AS 2017. Effects of fat sources in sow on the fatty acid profiles and fat globule size of milk and immunoglobulins of sows and piglets. Animal Feed Science and Technology 234, 217-227.

Banchero GE, Milton JTB, Lindsay DR, Martin GB and Quintans G 2015. Colostrum production in ewes: a review of regulation mechanisms and of energy supply. Animal 9, 831-837.

Barrington GM, McFadden TB, Huyler MT and Besser TE 2001. Regulation of colostrogenesis in cattle. Livestock Production Science 70, 95-104.

Bartol FF, Wiley AA, George AE, Miller DJ and Bagnell CA 2017. Postnatal reproductive development and the lactocrine hypothesis. Journal of Animal Science 95, 2200-2210.

Bee G 2000. Dietary conjugated linoleic acid alters adipose tissue and milk lipids of pregnant and lactating sows. Journal of Nutrition 130, 2292-2298.

Boonraungrod N, Sutthiya N, Kumwan P, Tossakui P, Nuntapaitoon M, Muns R and Tummaruk P 2018. Control of parturition in swine using PGF2alpha in combination with Carbetocin. Livestock Science, in press.

Decaluwé R, Maes D, Cools A, Wuyts D, De Smet S, Marescau B, De Deyn PP and Janssens GPJ 2014. Effect of peripartal feeding strategy on colostrum yield and composition in sows. Journal of Animal Science 92, 3557-3567.

Decaluwé R, Maes D, Declerck I, Cools A, Wuyts D, De Smet S and Janssens GPJ 2013. Changes in back fat thickness during late gestation predict colostrum yield in sows. Animal 7, 1999-2007.

Declerck I, Dewulf J, Sarrazin S and Maes D 2016. Long-term effects of colostrum intake in piglet performance and mortality. Journal of Animal Science 94, 1633-1643.

Devillers N, Farmer C, Le Dividich J and Prunier A 2007. Variability of colostrum yield and colostrum intake in swine. Animal 1, 1033-1041.

Devillers N, van Milgen J, Prunier A and Le Dividich J 2004. Estimation of colostrum intake in the neonatal pig. Animal Science 78, 305-313.

Farmer C, Lessard M, Knight CH and Quesnel H 2017. Oxytocin injections in the postpartal period affect mammary tight junctions in sows. Journal of Animal Science 95, 3532-3539.

Farmer C, Robert S and Rushen J 1998. Bromocriptine given orally to periparturient or lactating sows inhibits milk production. Journal of Animal Science 76, 750-757.

Farmer C and Quesnel H 2009. Nutritional, hormonal and environmental effects on colostrum in sows. Journal of Animal Science 87 (Suppl. 1), 56-65.

Flummer C and Theil PK 2012. Effect of beta-hydroxy beta-methyl butyrate supplementation of sows in late gestation and lactation on sow production of colostrum and milk and piglet performance. Journal of Animal Science 90, 372-374.

Foisnet A, Farmer C, David C and Quesnel H 2010a. Relationship between colostrum production by primiparous sows and sow physiology around parturition. Journal of Animal Science 88, 1672-1683.

Foisnet A, Farmer C, David C and Quesnel H 2010b. Progestagen treatment during late pregnancy did not reduce colostrum yield in primiparous sows. Journal of Animal Science 88, 1684-1693.

Foisnet A, Farmer C, David C and Quesnel H 2011. Farrowing induction induced transient alterations in prolactin concentrations and colostrum composition in primiparous sows. Journal of Animal Science 89, 3048-3059.

Gross JJ, Kessler EC, Bjerre-Harpoth V, Dechow C, Baumrucker CR and Bruckmaier RM 2014. Peripartal progesterone and prolactin have little effect on the rapid transport of immunoglobulin $\mathrm{G}$ into colostrum of dairy cows. Journal of Dairy Science 97, 2923-2931.

Hartmann PE, Whitely JL and Willcox DL 1984. Lactose in plasma during lactogenesis, established lactation and weaning in sows. Journal of Physiology 347, 453-463.

Hasan S, Junnikkala S, Peltoniemi 0, Paulin L, Lyyski A, Vuorenmaa J and Oliviero C 2018. Dietary supplementation with yeast hydrolysate in pregnancy influences colostrum yield and gut microbiota of sows and piglets after birth. PLoS One 13, e0197586.

Head RH and Williams IH 1991. Mammogenesis is influenced by pregnancy nutrition. In Manipulating pig production III (ed. ES Batterham), p 33. Australasian Pig Science Association, Werribee, VIC, Australia. 


\section{Quesnel and Farmer}

Huang SC, Hu Z, Hasler-Rapacz J and Rapacz J 1992. Preferential mammary storage and secretion of immunoglobulin gamma (IgG) subclasses in swine. Journal of Reproductive Immunology 21, 15-28.

Kensinger RS, Collier RJ and Bazer FW 1986. Ultrastructural changes in porcine mammary tissue during lactogenesis. Journal of Anatomy 145, 49-59.

Krogh U, Flummer C, Jensen SK and Theil PK 2012. Colostrum and milk production of sows is affected by dietary conjugated linoleic acid. Journal of Animal Science 90, 366-368.

Krogh U, Pksbjerg N, Purup S, Ramackers P and Theil PK 2016. Colostrum and milk production in multiparous sows fed supplementary arginine during gestation and lactation. Journal of Animal Science 94, 22-25.

Linzell JL, Mepham TB, Annison EF and West CE 1969. Mammary metabolism in lactating sows: arteriovenous differences of milk precursors and the mammary metabolism of [14C]glucose and [14 C]acetate. British Journal of Nutrition 23, 319-332.

Loisel F, Farmer C, Ramaekers P and Quesnel H 2013. Effect of high dietary fiber during late pregnancy on sow physiology, colostrum production, and piglet performance. Journal of Animal Science 91, 5269-5279.

Loisel F, Farmer C, Ramaekers P and Quesnel H 2014. Colostrum yield and piglet growth during lactation are related to gilt metabolic and hepatic status prepartum. Journal of Animal Science 92, 2931-2941.

Loisel F, Farmer C, van Hees $\mathrm{H}$ and Quesnel H 2015. Relative prolactin to progesterone concentrations around farrowing influence sow colostrum yield. Domestic Animal Endocrinology 53, 35-41.

Miller HM, Foxcroft GR and Aherne FX 2004. Increasing feed intake in late gestation does not affect plasma progesterone concentration in the sow. Theriogenology 62, 1618-1626.

Nissen S, Faidley TD, Zimmerman DR, Izard R and Fisher CT 1994. Colostral milk fat percentage and pig performance are enhanced by feeding the leucine metabolite beta-hydroxy-beta-methyl butyrate to sows. Journal of Animal Science 72, 2331-2337.

Otto MA, Machado AP, Moreira LP, Bernardi ML, Coutinho ML, Vaz IS Jr, Wentz I and Bortolozzo FP 2017. Colostrum yield and litter performance in multiparous sows subjected to farrowing induction. Reproduction in Domestic Animals 52, 749-755.

Palombo V, Loor JJ, D'Andrea M, Vailati-Riboni M, Shazad K, Krogh U and Theil PK 2018. Transcriptional profiling of swine mammary gland during the transition from colostrogenesis to lactogenesis using RNA sequencing. BMC Genomics 19, 322.

Quesnel H 2011. Colostrum production by sows: variability of colostrum yield and immunoglobulin G concentrations. Animal 5, 1546-1553.

Quesnel H, Farmer C and Devillers N 2012. Colostrum intake: influence on piglet performance and factors of variation. Livestock Science 145, 105-114.

Quesnel H, Farmer C and Theil PK 2015. Colostrum and milk production. In The gestating and lactating sow (ed. C Farmer), pp. 173-192. Wageningen Academic Publishers, Wageningen, the Netherlands.

Quesnel H, Ramaekers P, van Hees H and Farmer C 2013. Short communication: relations between peripartum concentrations of prolactin and progesterone in sows and piglet growth in early lactation. Canadian Journal of Animal Science 93, 109-112.

Rooke JA, Bland IM and Edwards SA 1998. Effect of feeding tuna oil or soyabean oil as supplements to sows in late pregnancy on piglet tissue composition and viability. British Journal of Nutrition 80, 273-280.

Rooke JA, Sinclair AG, Edwards SA, Cordoba R, Pkiyach R, Penny PC, Penny P, Finch AM and Horgan GW 2001. The effect of feeding salmon oil to sows throughout pregnancy on pre-weaning mortality of piglets. Animal Science 73, 489-500.

Santos de Aquino R, Dutra Junior WM, Manso HECC, MansoFilho HC, Kutschenko M, Nogueira ET and Watford M 2014. Glutamine and glutamate (AminoGut) supplementation influences sow colostrum and mature milk composition. Livestock Science 169, 112-117.

Schnulle PM and Hurley WL 2003. Sequence and expression of the FcRn in the porcine mammary gland. Veterinary Immunology and Immunopathology 91, 227-231.

Shen Y, Wan H, Zhu J, Fang Z, Che L, Xu S, Lin Y, Li J and Wu D 2015. Fish oil and olive oil supplementation in late pregnancy and lactation differentially affect oxidative stress and inflammation in sows and piglets. Lipids 50, 647-658.

Taverne M, Bevers M, Bradshaw JMC, Dieleman SJ, Willemse AH and Porter DG 1982. Plasma concentrations of prolactin, progesterone, relaxin, and oestradiol- $17 \beta$ in sows with progesterone, bromocriptine or indomethacin during late pregnancy. Journal of Reproduction and Fertility 65 , 85-96.

Theil PK, Flummer C, Hurley WL, Kristensen NB, Labouriau R and Sørensen MT 2014a. Mechanistic model to predict colostrum intake based on deuterium oxide dilution technique and impact of of gestation and prefarrowing diets on piglet intake and sow yield of colostrum. Journal of Animal Science 92 5507-5519.

Theil P, Lauridsen C and Quesnel H 2014b. Neonatal piglet survival: Impact of sow nutrition around parturition on fetal glycogen deposition and production and composition of colostrum and transient milk. Animal 8 1021-1030.

Vadmand CN, Krogh U, Hansen CF and Theil PK 2015. Impact of sow and litter characteristics on colostrum yield, time for onset of lactation, and milk yield of sows. Journal of Animal Science 93, 2488-2500.

Vanderhaeghe C, Dewulf J, Jourquin J, De Kruif A and Maes D 2011. Incidence and Prevention of Early Parturition in Sows. Reproduction in Domestic Animals 46, 428-433.

Wavreille J, Planchon V, Renaville R, Forier R, Agneessens R and Bartiaux-Thill N 2010. Effet d'un produit fermenté de pomme de terre dans l'aliment de la truie en maternité sur les performances des truies et des porcelets allaités. Journées de la Recherche Porcine 42, 133-134.

Wu F, Li PL, Bai LL, Liu H, Lai CH, Thacker PA and Wang FL 2015. Responses in colostrum production and immunoglobulin concentrations to conjugated linoleic acid fed to multiparous sows during late gestation. Animal Feed Science and Technology 210, 200-208. 